\title{
Different Regulation of p53 Expression by Cadmium Exposure in Kidney, Liver, Intestine, Vasculature, and Brain Astrocytes
}

\author{
Jin-Yong Lee ${ }^{1}$, Maki Tokumoto ${ }^{1}$, Yuta Hattori ${ }^{1,2}$, Yasuyuki Fujiwara ${ }^{1,3}$, Akinori Shimada ${ }^{4}$ and Masahiko Satoh ${ }^{1}$ \\ 'Laboratory of Pharmaceutical Health Sciences, School of Pharmacy, Aichi Gakuin University, \\ 1-100 Kusumoto-cho, Chikusa-ku, Nagoya 464-8650, Japan \\ ${ }^{2}$ Department of Preventive Medicine, Graduate School of Medicine, Nagoya University, \\ 65 Tsurumai-cho, Showa-ku, Nagoya 466-8550, Japan \\ ${ }^{3}$ Department of Environmental Health, School of Pharmacy, Tokyo University of Pharmacy and Life Sciences, \\ 1432-1 Horinouchi, Hachioji, Tokyo 192-0392, Japan \\ ${ }^{4}$ Laboratory of Pathology, Department of Medical Technology, School of Life and Environmental Science, \\ Azabu University, 1-17-71 Fuchinobe, Chuo-ku, Sagamihara, Kanagawa 252-5201, Japan
}

(Received November 14, 2015; Revised December 18, 2015; Accepted January 4, 2016)

\begin{abstract}
Chronic exposure to cadmium $(\mathrm{Cd})$ is known to adversely affect renal function. Our previous studies indicated that $\mathrm{Cd}$ induces $\mathrm{p} 53$-dependent apoptosis by inhibiting gene expression of the ubiquitin-conjugating enzyme (Ube) $2 \mathrm{~d}$ family in both human and rat proximal tubular cells. In this study, the effects of $\mathrm{Cd}$ on protein expression of p53 and apoptotic signals in the kidney and liver of mice exposed to $\mathrm{Cd}$ for 12 months were examined, as well as the effects of $\mathrm{Cd}$ on p53 protein levels and gene expression of the Ube2d family in various cell lines. Results showed that in the kidney of mice exposed to $300 \mathrm{ppm}$ Cd for 12 months, there was overaccumulation of p53 proteins in addition to the induction of apoptosis, which was triggered specifically in the proximal tubules. Interestingly, the site of apoptosis was the same as that of p53 accumulation in the proximal tubules. In the liver of mice chronically exposed to $\mathrm{Cd}$, gene expression of the Ube2d family tended to be slightly decreased, together with slight apoptosis without the accumulation of p53 protein. In rat small intestine epithelial (IEC-6) cells, Cd decreased not only the p53 protein level but also gene expression of Ube2d1, Ube2d2 and Ube2d4. In human brain microvascular endothelial cells (HBMECs), Cd did not suppress gene expression of the Ube2d family, but increased the p53 protein level. In human brain astrocytes (HBASTs), Cd only increased gene expression of UBE2D3. These results suggest that $\mathrm{Cd}$-induced apoptosis through p53 protein is associated with renal toxicity but not hepatic toxicity, and the modification of p53 protein by $\mathrm{Cd}$ may vary depending on cell type.
\end{abstract}

Key words: Cadmium, p53 protein, Ube2d family, Apoptosis, Renal toxicity

\section{INTRODUCTION}

Cadmium $(\mathrm{Cd})$ is a ubiquitous toxic heavy metal emanating from industrial and agricultural sources (1). Cd exposure is considered to cause damage of vital tissues such as the kidney, liver, heart, brain and testis (2-4). The liver and kidney are especially sensitive to the toxic effect of $\mathrm{Cd}$ (4).

Correspondence to: Masahiko Satoh, Laboratory of Pharmaceutical Health Sciences, School of Pharmacy, Aichi Gakuin University, 1-100 Kusumoto-cho, Chikusa-ku, Nagoya 464-8650, Japan E-mail: masahiko@dpc.agu.ac.jp

This is an Open-Access article distributed under the terms of the Creative Commons Attribution Non-Commercial License (http:// creativecommons.org/licenses/by-nc/3.0) which permits unrestricted non-commercial use, distribution, and reproduction in any medium, provided the original work is properly cited.
The biological half-life of $\mathrm{Cd}$ is so long (10 30 years) in the human body that chronic low-level $\mathrm{Cd}$ exposure brings about the accumulation of $\mathrm{Cd}$ in the kidney (4). Cd induces apoptosis in proximal tubular cells through several pathways, including the endoplasmic reticulum (ER)-mediated pathway via ER stress and calcium release, and the mitochondria-mediated pathway via direct and indirect activation of mitochondria (5). In addition, our recent studies demonstrated that $\mathrm{Cd}$ induced $\mathrm{p} 53$-dependent apoptotic cell death in renal proximal tubules both in vitro and in vivo (6) and in human proximal tubular cells (on submission). p53 is a short-lived protein, and under normal conditions is immediately degraded by the ubiquitin-proteasome system (UPS) (7-9). In MCF7 human breast carcinoma cells, ubiquitination of p53 is mediated by UBE2D2 and UBE2D3, which are members of the ubiquitin-conjugating enzyme (Ube) $2 d$ 
family, an E2 ubiquitin-conjugating enzyme family in the UPS (10). Cd was found to suppress the gene expression of all the Ube $2 \mathrm{~d}$ family members (Ube2d1, Ube2d2, Ube $2 \mathrm{~d} 3$ and Ube2d4), and induced accumulation and phosphorylation of $\mathrm{p} 53$, followed by $\mathrm{p} 53$-dependent apoptotic cell death in renal proximal tubules both in vitro and in vivo (6). In this study, we investigated the characteristics of $\mathrm{p} 53$ protein expression and the occurrence of apoptosis not only in the kidney but also in the liver of mice chronically exposed to Cd for 12 months.

In addition to the liver and kidney, the brain and gastrointestinal tract are also thought to be targets of $\mathrm{Cd}(2,3)$. There is variation in the sensitivity of individual tissues to $\mathrm{Cd}$ induced damage (11). Therefore, it was also examined whether $\mathrm{Cd}$ affects the protein level of p53 and gene expression of the Ube2d family, in such several cell lines as rat small intestine epithelial (IEC-6) cells, human brain microvascular endothelial cells (HBMECs) and human brain astrocytes (HBASTs).

\section{MATERIALS AND METHODS}

Animals. All animal experiments were performed in accordance with the Regulation on Animal Experimentation at School of Pharmacy, Aichi Gakuin University, Nagoya, Japan. All procedures to maintain and use mice were approved by the Animal Care and Use Committee for School of Pharmacy, Aichi Gakuin University, Nagoya, Japan. Four-week-old female C57BL/6J mice were purchased from CLEA Japan (Tokyo, Japan) and routinely bled in the vivarium of the laboratory animal facility of Aichi Gakuin University. The mice were caged in a ventilated animal room at $23 \pm 1{ }^{\circ} \mathrm{C}$ with relative humidity, and a $12 \mathrm{hr}$ light-dark cycle. After an adaptation period of one week, mice were randomly assigned to control or experimental groups, with $5 \sim 6$ mice per group. Control mice were fed standard laboratory chow, experimental mice were fed chow containing 300 ppm Cd (Oriental-BioService, Kyoto, Japan). All mice had unlimited access to tap water. After 12 months of $\mathrm{Cd}$ exposure, the kidney, liver, and serum were removed from each mouse under ether anesthesia.

GOT and GPT activities. To evaluate the hepatotoxicity, the activities of glutamic oxaloacetic transaminase (GOT) and glutamate pyruvate transaminase (GPT) in the serum were examined. The automatic dry-chemistry analyzer system (Spotchem EZ SP-4430; Arkray, Kyoto, Japan) was used to determine the activities.

p53 protein level. Each mouse liver was homogenized in nine volumes of low-salt RIPA buffer and the homogenate was centrifuged at $10,000 \times g$ for $10 \mathrm{~min}$ at $4^{\circ} \mathrm{C}$. Protein levels of $\mathrm{p} 53$ in the supernatant were quantified using a p53 Enzyme Immunometric Assay kit (Assay Designs, Ann
Arbor, MI, USA). Total protein concentration was measured using the Quick Start Protein Assay (Bio-Rad, Hercules, CA, USA), to normalize p53 levels.

Detection of apoptosis and p53 in tissue sections. The kidney and liver were fixed in $10 \%(\mathrm{v} / \mathrm{v})$ neutral buffered formalin solution and embedded in paraffin. Deparaffinized serial tissue sections of $5 \mu \mathrm{m}$ thickness were used for immunohistochemical staining of p53 and for apoptosis detection. For immunohistochemical staining of p53, antigen retrieval was conducted for $30 \mathrm{~min}$ at $90^{\circ} \mathrm{C}$ in $0.1 \mathrm{M}$ boric acid, $\mathrm{pH}$ 7.0. After antigen retrieval, kidney and liver sections were quenched in $0.3 \%(\mathrm{v} / \mathrm{v})$ hydrogen peroxide for $10 \mathrm{~min}$ and then stained using anti-p53 antibody (Abcam, Cambridge, MA, USA). The HistoMouse ${ }^{\mathrm{TM}}$-Plus kit (Invitrogen, Grand Island, NY, USA) was used to detect p53 antibody. Apoptosis was detected using the TACS $^{\circledR} 2$ TdT-DAB in situ apoptosis detection kit (Trevigen, Gaithersburg, MD, USA). Microscopy images were obtained using a BIOREVO BZ-9000 microscope (Keyence, Osaka, Japan).

Cell culture and Cd treatment. IEC-6 cells were purchased from DS Pharm Biomedical (Osaka, Japan), and cultured in Dulbecco's modified Eagle's medium (SigmaAldrich, St. Louis, MO, USA), supplemented with $10 \%$ fetal bovine serum (FBS) (Gibco, Grand Island, NY, USA), $25 \mathrm{U} / \mathrm{mL}$ penicillin and $25 \mu \mathrm{g} / \mathrm{mL}$ streptomycin at $37^{\circ} \mathrm{C}$ in a humidified incubator containing $5 \% \mathrm{CO}_{2}$. IEC- 6 cells were transferred to testing plates (24-well plates for Giemsa staining; 6-well plates for real-time RT PCR; $6 \mathrm{~cm}$ plates for western blotting) at $2.5 \times 10^{4}$ cells $/ \mathrm{cm}^{2}$ and cultured for $48 \mathrm{hr}$. The culture medium was then discarded and the cells treated with $\mathrm{Cd}\left(\mathrm{CdCl}_{2}\right)$ (Wako Pure Chemical Industries, Osaka, Japan) in serum-free culture medium for $24 \mathrm{hr}$.

HBMECs were purchased from DS Pharm Biomedical, and cultured on collagen I-coated dishes (IWAKI, Tokyo, Japan) at $37^{\circ} \mathrm{C}$ in a humidified incubator containing $5 \%$ $\mathrm{CO}_{2}$. The culture medium HuMedia-EG2 (Kurabo, Osaka, Japan) consisted of the base medium (HuMedia-EB2) supplemented with $2 \% \mathrm{FBS}, 10 \mathrm{ng} / \mathrm{mL}$ recombinant epidermal growth factor, $5 \mathrm{ng} / \mathrm{mL}$ recombinant basic fibroblast growth factor, $10 \mu \mathrm{g} / \mathrm{mL}$ heparin, and $1 \mu \mathrm{g} / \mathrm{mL}$ hydrocortisone. HBMECs were transferred to testing plates (24-well plates for Giemsa staining; 6-well plates for real-time RT PCR; $6 \mathrm{~cm}$ plates for western blotting) at $1.0 \times 10^{4}$ cells $/ \mathrm{cm}^{2}$ and cultured for $48 \mathrm{hr}$. The culture medium was discarded and cells treated with $\mathrm{Cd}$ in serum-containing culture medium.

HBASTs were purchased from DS Pharm Biomedical, and cultured on collagen I-coated dishes (IWAKI) at $37^{\circ} \mathrm{C}$ in a humidified incubator containing 5\% $\mathrm{CO}_{2}$. HBASTs were cultured in CSC complete medium kit with serum and Attachment Factor ${ }^{\mathrm{TM}}$ (Cell Systems, Kirkland, WA, USA). The HBASTs were transferred to testing plates (24-well plates for Giemsa staining; 6-well plates for real-time RT 
PCR) at $4.0 \times 10^{4}$ cells $/ \mathrm{cm}^{2}$ and cultured for $48 \mathrm{hr}$. The culture medium was discarded and the cells treated with $\mathrm{Cd}$ in serum-containing culture medium.

Cell morphology. After Cd treatment, the cell layer was washed with calcium- and magnesium-free phosphatebuffered saline (PBS; Nissui Pharmaceutical, Tokyo, Japan), fixed with May-Grunwald stain solution (Merck, Darmstadt, Germany) for $3 \mathrm{~min}$, and stained with Giemsa stain solution (Merck) for $30 \mathrm{~min}$ at room temperature. Cell morphology was examined microscopically using the OLYMPUS CK2 microscope (OLYUMUS, Tokyo, Japan) at 100× magnification.

RNA extraction and real-time RT-PCR. Cd-treated cells were washed twice with ice-cold PBS, and total RNA extracted with the Quick Gene RNA cultured cell kit S (Fujifilm, Tokyo, Japan). cDNA was generated from total RNA using the PrimeScript reverse transcription (RT) reagent kit (Perfect Real Time; TaKaRa Bio, Shiga, Japan). Real-time PCR was performed with the SYBR Premix Ex Taq II (Perfect Real Time, TaKaRa Bio), and a thermal cycler dice real time system (TaKaRa Bio). PCR conditions were: $10 \mathrm{~s}$ hot-start at $95^{\circ} \mathrm{C}$ followed by 40 cycles of $5 \mathrm{~s}$ at $95^{\circ} \mathrm{C}$ and $30 \mathrm{~s}$ at $60^{\circ} \mathrm{C}$. The oligonucleotide sequences of the primers were as follows: sense, $5^{\prime}$-GAGTAATTTGGGGTTTGTCTTGG-3', and antisense, 5'-CCTTTCTTTTGGATGGGTGAT-3', for the human $U B E 2 D 1$ gene; sense, 5'TTGTCCATCTGTTCTCTGTTGTG-3', and antisense, 5'TCCATTCCCGAGCTATTCTGT-3', for the human UBE2D2 gene; sense, 5'-GGTGCAGCCCCTGTCTAACT-3', and antisense, 5'-GGCCTTGTAGGTGTGTGCTATCTC-3', for the human UBE2D3 gene; sense, 5'-TGGTCTCCAGCGTTGACTG-3', and antisense, 5'-GGCCTTGTAGGTGTGTGCTATCTC-3', for the human UBE2D4 gene; sense, 5'GCACCGTCAAGGCTGAGAAC-3', and antisense, 5'TGGTGAAGACGCCAGTGGA-3', for the human $G A P D H$ gene; sense, 5'-CGGGACCCGTGGGAGATGACTTGTT-3', and antisense, 5'-GACTCCACCTTGATAGGCGCTGTCG3', for the rat Ube2dl gene; sense, 5'-GCACATGTTTACCTGACACAGCA-3', and antisense, 5'-CGGAGAACTGGCTTCTCACAC-3', for the rat Ube2d2 gene; sense, 5'GACGGTTTTCAGGGTTCTGG-3', and antisense, 5'TCTTCTTCTCACACCGGCTCT-3', for the rat Ube $2 d 3$
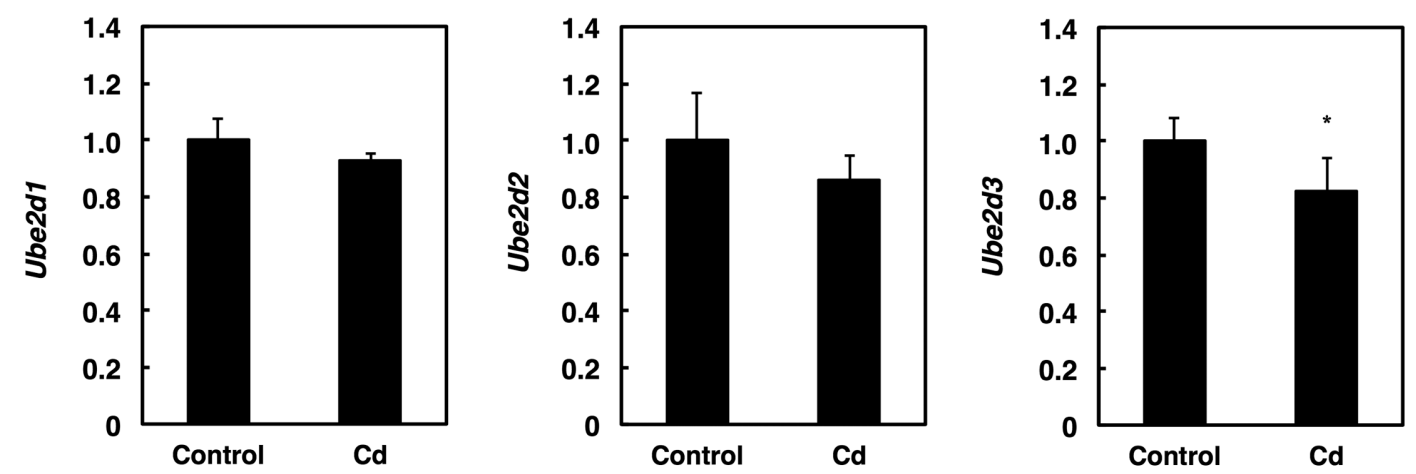

(A)

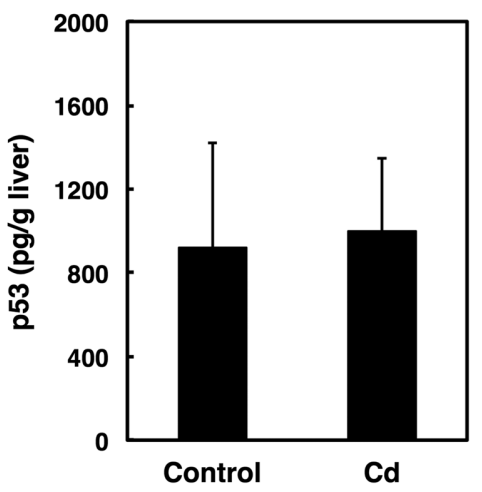

(B)

Fig. 1. Effects of chronic exposure to $\mathrm{Cd}$ on gene expression of the Ube2d family and on protein levels of p53 in the liver of mice. (A) Ube2d family gene expression in the liver of mice exposed to $\mathrm{Cd}$ for 12 months. mRNA levels were measured by real-time RT-PCR and normalized to $\beta$-actin. Data are presented as a ratio of treated groups: controls. (B) Protein levels of p53 in the liver of mice exposed to $\mathrm{Cd}$ for 12 months, determined using ELISA. (A,B) Values are mean \pm S.D. ( $n=5$ or 6$)$. ${ }^{*}$ Significantly different from the control group, $p<0.05$. 
gene; sense, 5'-AGCCTTCTCCAGGCATAACC-3', and antisense, 5'-TAGGTTGGGGACCTTTACCC-3', for the rat Ube2d4 gene; sense, 5'-CATGGCCTCCAAGGAGTAAG3', and antisense, 5'-GGTCTGGGATGGAATTGTGA-3', for the rat Gapdh gene; sense, 5'-ACAACAGGCACGCAAGAG-3', and antisense, 5'-GAACGAAGGACACGGCAAAC-3', for the mouse Ube2dl gene; sense, 5'-ATGC-
AAAGGTGTTGGTTGCT-3', and antisense, 5'-TGCTCATGTTTCCCAGGTTC-3', for the mouse Ube2d2 gene; sense, 5'-CAGTAATGGCAGCATTTGTCTTG-3', and antisense, 5'-GGGTCGTCTGGGTTTGGAT-3', for the mouse Ube $2 d 3$ gene; sense, 5'-CCTAAGGCCAACCGTGAAAA3', and antisense, 5'-AGCCATACAGGGACAGCACA-3', for the mouse $\beta$-actin gene.

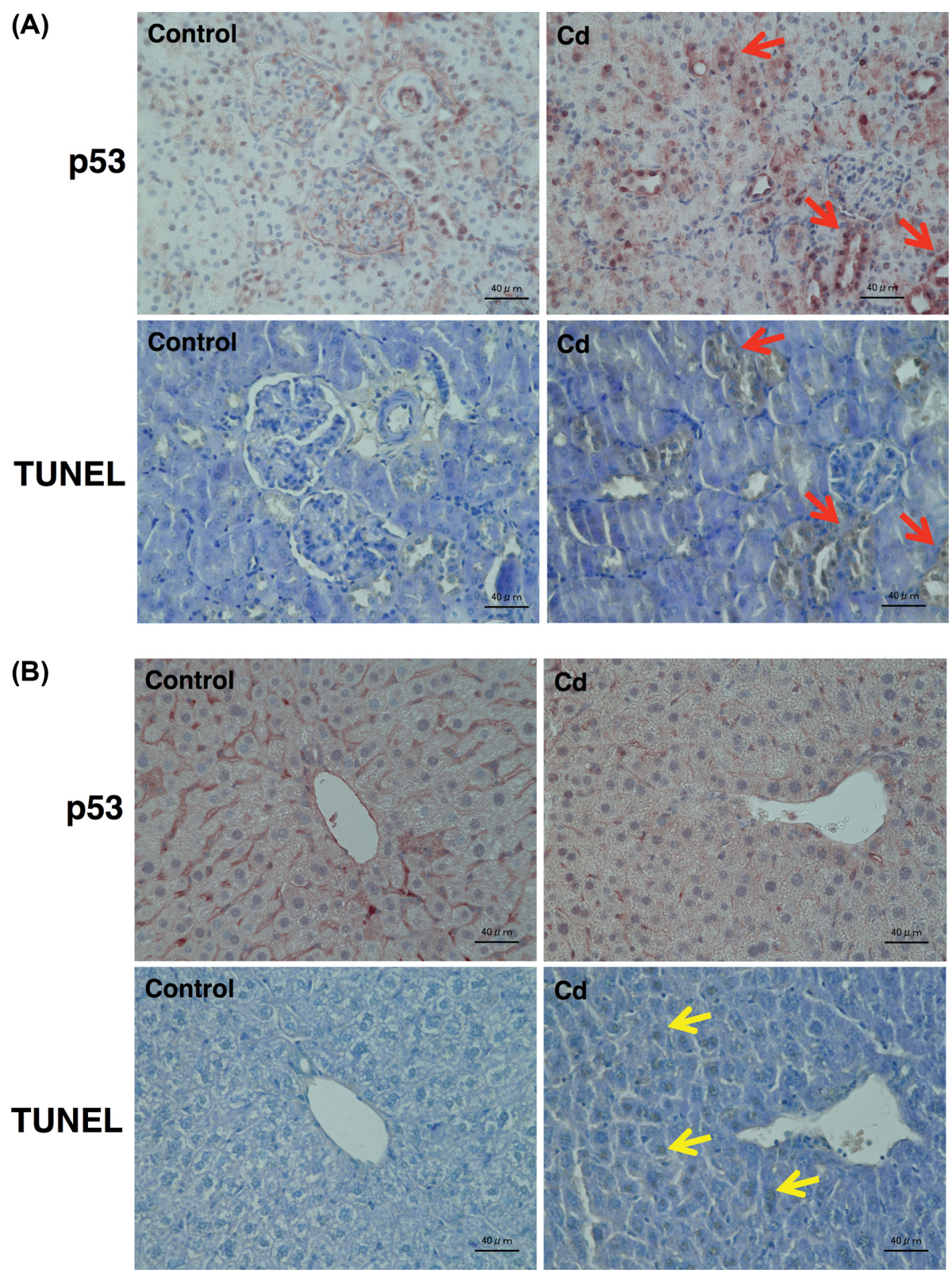

Fig. 2. Effects of chronic exposure for 12 months to $\mathrm{Cd}$ on protein expression of p53 and appearance of apoptosis in the kidney and liver of mice. (A) Representative images of p53 staining (upper panels) and TUNEL staining (lower panels) in the kidney of mice. Serial sections of kidney from control mice are shown in the left panels and those of Cd-exposed mice in the right panels. Red arrows indicate p53 expression (upper panel) and apoptotic cells (lower panel). Scale bar $=40 \mu \mathrm{m}$. Original magnification $\times 400$. (B) Representative images of p53 staining (upper panels) and TUNEL staining (lower panels) in the liver of mice. Serial sections of liver from control mice are shown in the left panels and those of Cd-exposed mice in the right panels. Yellow arrows indicate apoptotic cells (lower panel). Scale bar $=40 \mu \mathrm{m}$. Original magnification $\times 400$. 
Western blotting. After $\mathrm{Cd}$ treatment, cells were washed twice with ice-cold PBS and harvested in sodium dodecyl sulfate (SDS) buffer (2\% SDS, $50 \mathrm{mM}$ Tris [pH 6.8], 10\% glycerol). Protein concentrations were measured using the BCA protein assay kit (Thermo Fisher Scientific, Waltham, MA, USA). Protein was electrophoresed on SDS-polyacrylamide gels, transferred to polyvinylidene fluoride membranes (ATTO, Tokyo, Japan), and probed with antibodies against p53 (1:1000; Cell Signaling Technology, Danvers, MA, USA), GAPDH (1:2000; American Research Products, Waltham, MA, USA) or $\beta$-actin $(1: 1,000$; American Research Products, Waltham, MA, USA). Membranes were subsequently probed with horseradish peroxidase-conjugating secondary antibodies (1:10000; GE Healthcare, Tokyo, Japan), and protein detected by Chemi-Lumi one L (Nakalai tesque, Kyoto, Japan). Chemiluminescent images were obtained using an Image Quant LAS-3000 (Fujifilm, Tokyo, Japan) device.

Statistical analysis. Statistical analyses were performed using one-way analysis of variance (ANOVA). When the $\mathrm{F}$ value was significant $(p<0.05)$, Bonferroni's multiple $t$-test was performed for post-hoc comparisons $(p<0.05)$. Student $t$-test was performed for two-sample comparison $(p<$ $0.05)$.

\section{RESULTS}

The mouse kidney and liver. GOT activity in the serum of $\mathrm{Cd}$ exposed mice was $213.7 \pm 62.6 \mathrm{IU} / \mathrm{L}$ compared with $60 \pm 18.9 \mathrm{IU} / \mathrm{L}$ in that of control mice. GPT activity in the serum of $\mathrm{Cd}$ exposed mice was $63.7 \pm 19.7$ $\mathrm{IU} / \mathrm{L}$ compared with $23.6 \pm 6.1 \mathrm{IU} / \mathrm{L}$ in that of control mice. Similarly as the mild renal toxicity in the mice exposed to $300 \mathrm{ppm} \mathrm{Cd}$ for 12 months (6), chronic Cd exposure triggers mild hepatic toxicity. The only gene expression significantly decreased by $\mathrm{Cd}$ exposure was $\mathrm{Ube} 2 \mathrm{~d} 3$ in the liver (Fig. 1A). Hepatic p53 protein levels in mice chronically exposed to $\mathrm{Cd}$ were the same as that in control mice (Fig. 1B).

The kidney of mice exposed to $\mathrm{Cd}$ for 12 months showed both apoptosis and accumulation of p53 occurring in same positions on the proximal tubules (Fig. 2A). On the other hand, the accumulation of p53 was not observed, but slightly higher levels of apoptosis were detected, in the liver of mice exposed to $\mathrm{Cd}$ for 12 months compared with controls (Fig. 2B). Taken together, it is suggested that p53-dependent apoptosis by chronic $\mathrm{Cd}$ exposure is preferred in the kidney but not in the liver of mice.

Various cell lines. $\mathrm{Cd}$ exposure of IEC- 6 cells caused dose-dependent destruction of the cell layers (Fig. 3A). Gene expression of Ube2d1 and Ube2d4 was significantly decreased by as little as $2 \mu \mathrm{M} \mathrm{Cd}$ for $6 \mathrm{hr}$ (Fig. 3B). Cd treatment also tended to decrease gene expression of

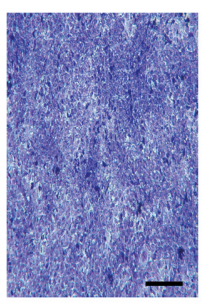

0

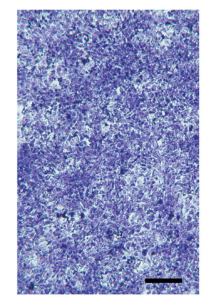

2

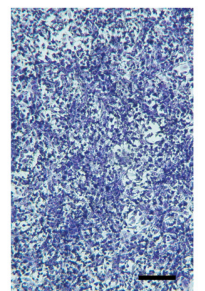

5

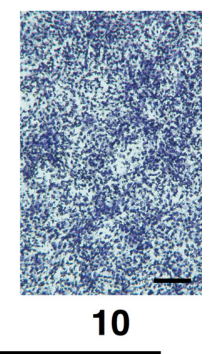

$\mathrm{Cd}(\mu \mathrm{M})$

(A)
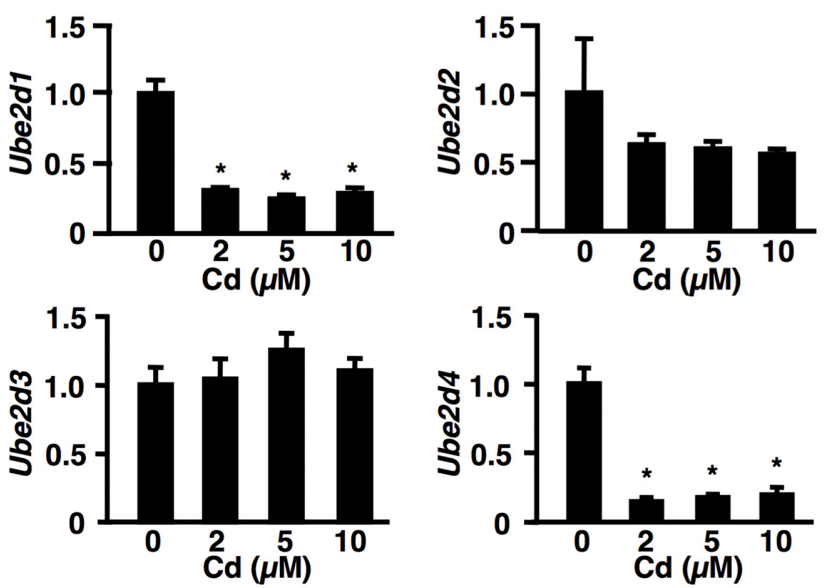

(B)

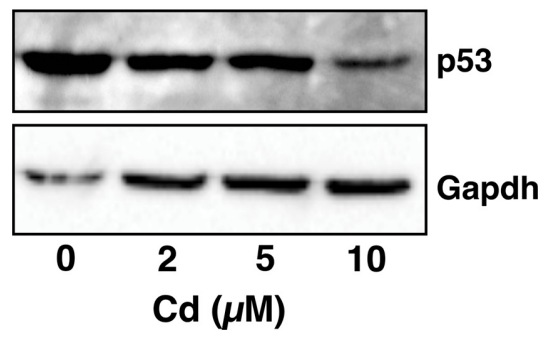

(C)

Fig. 3. Effects of $\mathrm{Cd}$ on gene expression of the Ube2d family and protein levels of p53 in IEC- 6 cells. (A) Cytotoxicity of IEC-6 cells treated with $\mathrm{Cd}\left(\mathrm{CdCl}_{2}\right)$ for $24 \mathrm{hr}$, using Giemsa staining. Scale bar $=250 \mu \mathrm{m}$. (B) mRNA level of Ube2d family in IEC-6 cells treated with $\mathrm{Cd}$ for $6 \mathrm{hr}$. mRNA levels were measured by real-time RT-PCR and normalized to Gapdh. Data presented as a ratio of treated cells : controls, values are mean \pm S.D. for 3 samples. ${ }^{*}$ Significantly different from the control group, $p<0.05$. (C) Protein level of p53 in IEC- 6 cells treated with $\mathrm{Cd}$ for $12 \mathrm{hr}$ detected by western blotting.

Ube2d2 (Fig. 3B) and markedly decreased protein levels of p53 (Fig. 3C). Despite Cd treatment suppressing the gene expression of the Ube2d family, p53 protein levels in IEC cells were decreased by $\mathrm{Cd}$ treatment.

Giemsa staining of HBMECs treated with $\mathrm{Cd}$ for $24 \mathrm{hr}$ showed disruption of the cell layers (Fig. 4A). Cd treat- 


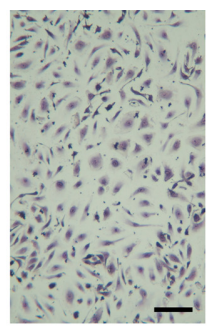

0

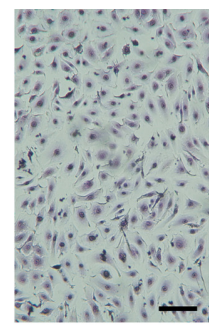

50

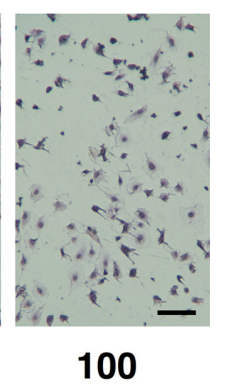

100

\section{$\mathrm{Cd}(\mu \mathrm{M})$}

(A)
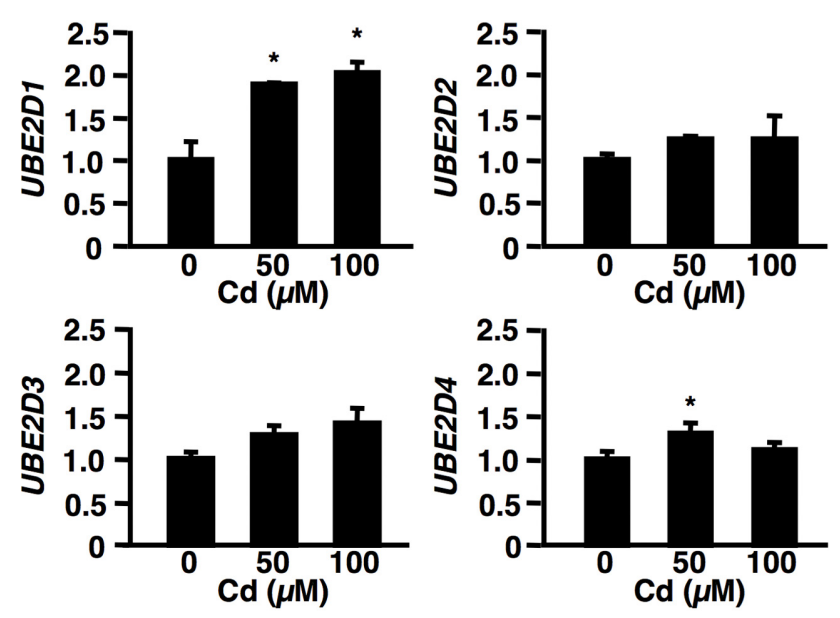

(B)

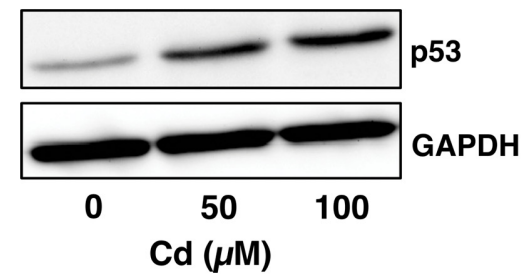

(C)

Fig. 4. Effects of $\mathrm{Cd}$ on gene expression of the Ube2d family and protein levels of p53 in HBMECs. (A) Cytotoxicity of HBMECs treated with $\mathrm{Cd}\left(\mathrm{CdCl}_{2}\right)$ for $24 \mathrm{hr}$, using Giemsa staining. Scale bar $=250 \mu \mathrm{m}$. (B) mRNA level of Ube2d family in HBMECs treated with $\mathrm{Cd}$ for $6 \mathrm{hr}$. mRNA levels were measured by realtime RT-PCR and normalized to GAPDH. Data presented as a ratio of treated cells : controls, values are mean \pm S.D. for 3 samples. *Significantly different from the control group, $p<0.05$. (C) Protein level of p53 in HBMECs treated with $\mathrm{Cd}$ for $12 \mathrm{hr}$, detected by western blotting.

ment of HBMECs for $6 \mathrm{hr}$ increased gene expression of UBE2D1 significantly. Gene expression of UBE2D4 was significantly increased by $50 \mu \mathrm{M}$ Cd treatment (Fig. 4B). Protein levels of p53 were increased by $\mathrm{Cd}$ treatment $(50 \mu \mathrm{M})$ and even at that low level, slight cell toxicity was evident (Fig. 4C). In HBMECs, Cd treatment increased p53

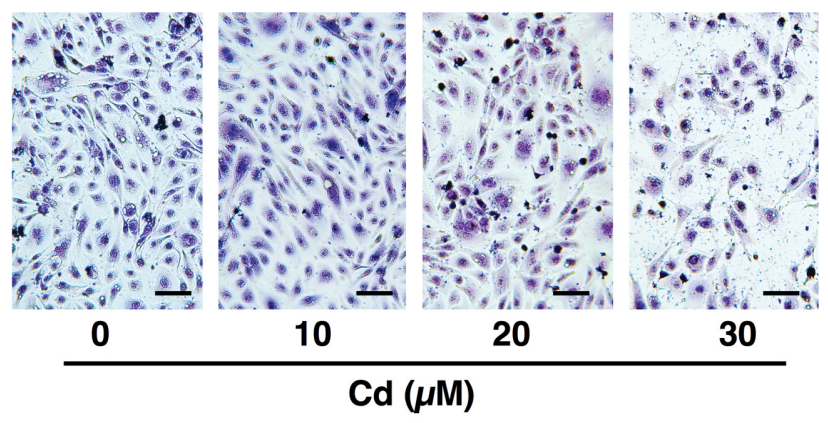

(A)
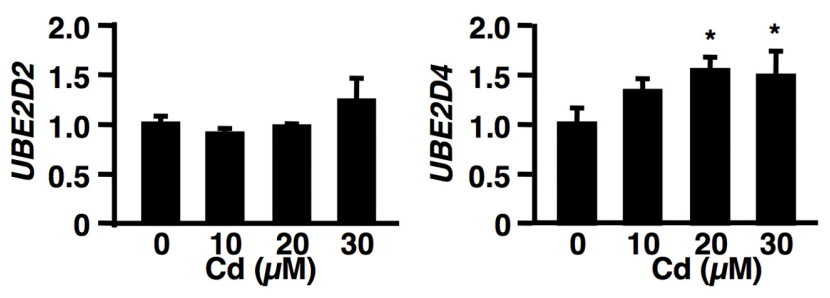

(B)

Fig. 5. Effects of $\mathrm{Cd}$ on gene expression of UBE2D2 and UBE2D4 in HBASTs. (A) Cytotoxicity of HBASTs treated with $\mathrm{Cd}\left(\mathrm{CdCl}_{2}\right)$ for $24 \mathrm{hr}$, cells viewed after Giemsa staining. Scale bar $=250 \mu \mathrm{m}$. (B) mRNA level of Ube2d family in HBASTs treated with Cd for $6 \mathrm{hr}$. mRNA levels were measured by real-time RT-PCR and normalized to GAPDH. Data presented as a ratio of treated cells: controls, values are mean \pm S.D. for 3 samples. ${ }^{*}$ Significantly different from the control group, $p<0.05$.

protein levels with the increase in gene expression of parts of the Ube2d family.

Cd toxicity was seen in HBASTs with 20 and $30 \mu \mathrm{M}$ treatment (Fig. 5A). Cd treatment increased UBE2D4 gene expression significantly, with no effect on $U B E 2 D 2$ gene expression (Fig. 5B). However, in HBASTs, neither gene expression of UBE2D1 and UBE2D3 nor protein expression of p53 was detected with the primers and antibodies described.

These data suggest that the modification of $\mathrm{p} 53$ protein by $\mathrm{Cd}$ treatment may have cell variability.

\section{DISCUSSION}

Our previous study demonstrated that 12-month Cd exposure decreased gene expression of Ube2d family, increased p53 protein levels and induced apoptosis in the kidney of mice (6). In this study, we examined the effects of $\mathrm{Cd}$ on gene expression of Ube2d family and protein levels of p53 in the liver of mice exposed to $\mathrm{Cd}$ for 12 months. It was also examined the effects of $\mathrm{Cd}$ on accumulation of p53 protein and occurrence of apoptosis with $5 \mu \mathrm{m}$ serial sections of the kidney and liver of mice exposed to $\mathrm{Cd}$ for 12 months. Although gene expression of Ube2d family in the kidney of mice was significantly decreased by chronic $\mathrm{Cd}$ 
exposure (6), that of Ube2d family in the liver of mice was slightly decreased by chronic $\mathrm{Cd}$ exposure (Fig. 1A). In a similar way of changes of gene expression of Ube2d family by $\mathrm{Cd}$ in the kidney and liver of mice, chronic $\mathrm{Cd}$ exposure increased p 53 protein levels in the kidney of mice (6); however, hepatic p53 protein levels of mice chronically exposed to $\mathrm{Cd}$ was same as that of control mice (Fig. 1B). The difference in response of the Ube2d family gene to Cd exposure in the kidney and liver of mice may have affected the level of protein expression of $\mathrm{p} 53$ in the two tissues.

Various proteins involved in UPS have been found to be associated with $\mathrm{Cd}$ toxicity in human-origin cultured cells $(12,13)$ in addition to the Ube2d family. Therefore, UPSrelated proteins other than the Ube2d family may be involved in Cd-toxicity in the liver or other tissues. This study demonstrated that chronic exposure to $\mathrm{Cd}$ triggered p53 dependent apoptosis in the kidney but not the liver. Indeed, p53 at gene and protein level was not regulated by Cd in HepG2 human hepatoma cell lines (14). The entire spectrum of p53 action is likely complex and cell type specific, as it has been implicated in both promoting and inhibiting apoptosis in multiple cell types (15). This study implicates that by inducing apoptosis with $\mathrm{Cd}$ in the liver as well as the kidney of mice, differences between the two tissues in their apoptosis-related gene response to $\mathrm{Cd}$ may be apparent.

Previous studies reported that $\mathrm{Cd}$ elicits toxic effects in microvascullar endothelial cells and astrocytes of mice and rats. $\mathrm{Cd}$ induces apoptosis through the activation of mitogen activated protein kinase (MAPK) activity in mouse microvascular endothelial cells (16). Moreover, Cd stimulates the expression of intracellular adhesion molecule-1 (ICAM-1), an indicator of blood-brain barrier (BBB) injury in mouse microvascular endothelial cells (17). Cd induces release intracellular $\mathrm{Ca}^{2+}$ level and oxidative stress in rat astrocytes $(18,19)$. We demonstrated that $\mathrm{Cd}$ increased $\mathrm{p} 53$ protein in human brain microvascular endothelial cells (Fig. 4C). Collectively, these findings suggest that $\mathrm{Cd}$ may be associated with neurological disorders.

Our recent study established that $\mathrm{Cd}$ changed the activities of various transcription factors in NRK-52E cells (20). A further study found that gene expression of each member of the Ube2d family is dependent on the activity of a transcription factor affected by $\mathrm{Cd}$ (on submission). This present study demonstrated that $\mathrm{Cd}$-induced change of gene expression of the Ube2d family varies between tissues and between cell lines. Therefore, the effects of $\mathrm{Cd}$ on the activities of transcription factors may be responsible for differences in gene expression of the Ube2d family in different tissues or cell lines.

\section{CONFLICT OF INTEREST}

Authors declare that they are no conflicts of interest.

\section{ACKNOWLEDGMENTS}

This research was supported, in part, as a study into the health effects of heavy metals by the Ministry of the Environment, Japan.

\section{REFERENCES}

1. Van Maele-Fabry, G., Lombaert, N. and Lison, D. (2016) Dietary exposure to cadmium and risk of breast cancer in postmenopausal women: A systematic review and meta-analysis. Environ. Int., 86, 1-13.

2. Nair, A.R., Degheselle, O., Smeets, K., Van Kerkhove, E. and Cuypers, A. (2013) Cadmium-induced pathologies: Where is the oxidative balance lost (or Not). Int. J. Mol. Sci., 14, 61166143.

3. Ninkov, M., Popov Aleksandrov, A., Demenesku, J., Mirkov, I., Mileusnic, D., Petrovic, A., Grigorov, I., Zolotarevski, L., Tolinacki, M., Kataranovski, D., Brceski, I. and Kataranovski, M. (2015) Toxicity of oral cadmium intake: Impact on gut immunity. Toxicol. Lett., 237, 89-99.

4. Järup, L. and Akesson, A. (2009) Current status of cadmium as an environmental health problem. Toxicol. Appl. Pharmacol., 238, 201-208.

5. Fujiwara, Y., Lee, J.Y., Tokumoto, M. and Satoh, M. (2012) Cadmium renal toxicity via apoptotic pathways. Biol. Pharm. Bull., 35, 1892-1897.

6. Tokumoto, M., Fujiwara, Y., Shimada, A., Hasegawa, T., Seko, Y., Nagase, H. and Satoh, M. (2011) Cadmium toxicity is caused by accumulation of p53 through the down-regulation of Ube2d family genes in vitro and in vivo. J. Toxicol. Sci., 36, 191-200.

7. Haupt, Y., Maya, R., Kazaz, A. and Oren, M. (1997) Mdm2 promotes the rapid degradation of p53. Nature, 387, 296-299.

8. Honda, R., Tanaka, H. and Yasuda, H. (1997) Oncoprotein MDM2 is a ubiquitin ligase E3 for tumor suppressor p53. FEBS Lett., 420, 25-27.

9. Kubbutat, M.H., Jones, S.N. and Vousden, K.H. (1997) Regulation of p53 stability by Mdm2. Nature, 387, 299-303.

10. Saville, M.K., Sparks, A., Xirodimas, D.P., Wardrop, J., Stevenson, L.F., Bourdon, J.C., Woods, Y.L. and Lane, D.P. (2004) Regulation of $\mathrm{p} 53$ by the ubiquitin-conjugating enzymes UbcH5B/C in vivo. J. Biol. Chem., 279, 42169-42181.

11. Swiergosz-Kowalewska, R. (2001) Cadmium distribution and toxicity in tissues of small rodents. Microsc. Res. Tech., 55, 208-222.

12. Lee, J.Y., Tokumoto, M., Fujiwara, Y. and Satoh, M. (2015) Involvement of ubiquitin-coding genes in cadmium-induced protein ubiquitination in human proximal tubular cells. J. Toxicol. Sci., 40, 901-908.

13. Du, K., Takahashi, T., Kuge, S., Naganuma, A. and Hwang, G.W. (2014) FBXO6 attenuates cadmium toxicity in HEK293 cells by inhibiting ER stress and JNK activation. J. Toxicol. Sci., 39, 861-866.

14. Urani, C., Melchioretto, P., Fabbri, M., Bowe, G., Maserati, E. and Gribaldo, L. (2014) Cadmium impairs p53 activity in HepG2 cells. ISRN Toxicol., 2014, 976428.

15. Bhattacharya, S., Ray, R.M. and Johnson, L.R. (2014) Cyclin- 
dependent kinases regulate apoptosis of intestinal epithelial cells. Apoptosis, 19, 451-466.

16. Jung, Y.S., Jeong, E.M., Park, E.K., Kim, Y.M., Sohn, S., Lee, S.H., Baik, E.J. and Moon, C.H. (2008) Cadmium induces apoptotic cell death through p38 MAPK in brain microvessel endothelial cells. Eur. J. Pharmacol., 578, 11-18.

17. Jeong, E.M., Moon, C.H., Kim, C.S., Lee, S.H., Baik, E.J., Moon, C.K. and Jung, Y.S. (2004) Cadmium stimulates the expression of ICAM-1 via NF-kappaB activation in cerebrovascular endothelial cells. Biochem. Biophys. Res. Commun., 320, 887-892.

18. Yang, C.S., Tzou, B.C., Liu, Y.P., Tsai, M.J., Shyue, S.K. and
Tzeng, S.F. (2008) Inhibition of cadmium-induced oxidative injury in rat primary astrocytes by the addition of antioxidants and the reduction of intracellular calcium. J. Cell. Biochem., 103, 825-834.

19. Jo, C. and Koh, Y.H. (2013) Cadmium induces N-cadherin cleavage via ERK-mediated $\gamma$-secretase activation in C6 astroglia cells. Toxicol. Lett., 222, 117-121.

20. Tokumoto, M., Lee, J.Y., Fujiwara, Y. and Satoh, M. (2014) Alteration of DNA binding activity of transcription factors in NRK-52E rat proximal tubular cells treated with cadmium. $J$. Toxicol. Sci., 39, 735-738. 